(2) Open Access Full Text Article

REVIEW

\title{
Abatacept in the treatment of polyarticular JIA: development, clinical utility, and place in therapy
}

This article was published in the following Dove Press journal:

Drug Design, Development and Therapy

25 January 2011

Number of times this article has been viewed

\author{
Ofra Goldzweig' \\ Philip J Hashkes ${ }^{2,3}$ \\ 'Rainbow Babies and Children's \\ Hospital, Cleveland, OH, USA; \\ ${ }^{2}$ Pediatric Rheumatology Unit, Shaare \\ Zedek Medical Center, Jerusalem, \\ Israel; ${ }^{3}$ Cleveland Clinic Lerner \\ Medical School of Case Western \\ Reserve University, Cleveland, $\mathrm{OH}$, \\ USA
}

Correspondence: Philip J Hashkes Pediatric Rheumatology Unit, Shaare Zedek Medical Center, PO Box 3235, Jerusalem 9103I, Israel

Tel + I 97226666242

Fax + I 97226555297

Email hashkesp@szmc.org.il

\begin{abstract}
Juvenile idiopathic arthritis (JIA) is a group of chronic arthritides affecting children. The polyarthritis category, affecting five or more joints in the first six months, tends to be more aggressive, leading to a destructive joint disease with significant morbidity, disability, and costs to society. The current treatment regimen, which primarily combines methotrexate and tumor necrosis factor alpha (TNF- $\alpha$ ) blockade, still leaves a significant group of patients with an inadequate response. Therefore, the development of new medications that act via other mechanisms of pathogenesis is necessary. T cell lymphocytes are key components in the immune reaction in JIA. Cytotoxic lymphocyte-associated antigen-4 (CTLA-4) is a potent inhibitor of the costimulation pathway necessary to activate $\mathrm{T}$ cells. Abatacept is a recombinant fusion protein comprising the extracellular part of human CTLA-4 connected to a modified Fc part of IgG-1. In a randomized, multinational, blinded withdrawal study in children with polyarticular JIA, abatacept was found to be effective in about $70 \%$ of the patients, including $39 \%$ of TNF- $\alpha$ blockade failures, with significantly fewer flares occurring during the withdrawal phase than in patients receiving placebo. Abatacept continued to show good efficacy in a three-year open-label extension study, with a beneficial effect on health-related quality of life. The safety profile of abatacept is generally good. In 2008, the US Food and Drug Administration approved abatacept for use in children over six years of age with JIA and a polyarticular course. In 2010, the European Medicines Agency gave approval for abatacept to be used in combination with methotrexate for those who fail at least one disease-modifying medication and TNF- $\alpha$ blockade.
\end{abstract}

Keywords: juvenile idiopathic arthritis, treatment, abatacept

\section{Introduction}

Juvenile idiopathic arthritis (JIA) is the most common chronic rheumatic condition in children, affecting approximately 1 in 1000 children. ${ }^{1}$ It is an inclusive term for a group of chronic inflammatory arthritides affecting children younger than 16 years of age, without another explanation. ${ }^{1,2}$ The categories are based on the presence or absence of systemic symptoms or psoriasis, the number of joints involved in the first six months of the disease, rheumatoid factor, and HLA B27 status (Table 1). The polyarthritis category includes children with five or more affected joints during the first six months of the disease, and is further subdivided according to rheumatoid factor status. This form of JIA tends to be more aggressive (especially rheumatoid factor-positive disease), causing joint destruction and disability early in its course, with radiographic changes evident at a mean of two years from disease onset. ${ }^{2}$ The inflammatory process can be difficult to control, and consequences include pain, disability, ${ }^{3}$ local and global growth impairment, ${ }^{4}$ and major insults to function and health-related quality of life for the 
Table I Categories of juvenile idiopathic arthritis

\begin{tabular}{ll}
\hline Category & Proportion of patients (\%) \\
\hline *Systemic & $5-10$ \\
Oligoarthritis & $40-50$ \\
Persistent oligoarthritis & $25-35$ \\
*Extended oligoarthritis & $15-20$ \\
Polyarthritis & $30-40$ \\
*Rheumatoid factor-negative & $25-35$ \\
*Rheumatoid factor-positive & 5 \\
Psoriatic arthritis & $5-10$ \\
Enthesitis-related arthritis & $5-10$ \\
Other (undifferentiated, overlaps & 10 \\
more than one category) &
\end{tabular}

more than one category)

Note: *Patients in these categories with polyarticular disease (and without active systemic features) were included in the abatacept trials.

patient and his/her family. ${ }^{5}$ A significant percentage of patients with polyarthritis continue to have active disease as adults. ${ }^{3,6}$ The disease affects multiple aspects of life, and carries a heavy economic burden for society. Understanding this has led to an earlier and more aggressive treatment regimen, with early introduction of disease-modifying antirheumatic drugs, particularly methotrexate. ${ }^{7,8}$ However, more than $30 \%$ of patients do not respond adequately to methotrexate, including higher doses given parenterally. ${ }^{89}$ Full remission is usually not achieved, even among responders. Therefore, new biologic medications based on an understanding of the immune pathogenesis of JIA have been developed. This has revolutionized the treatment of JIA, particularly in patients with a polyarticular course (Table 1). Polyarticular course includes patients with polyarthritis, extended oligoarthritis, and systemic arthritis evolving into a polyarticular course. Most studied are the tumor necrosis factor alpha (TNF- $\alpha$ ) blockers. ${ }^{10-12}$ More than $70 \%$ of patients with JIA having a polyarticular course and treated with TNF- $\alpha$ blocking agents respond significantly. However, a large proportion of children with polyarthritis still spend more than $60 \%$ of their time with active disease. ${ }^{13}$ For patients who do not respond adequately to TNF- $\alpha$ blocking agents, for whom effectiveness wears off, or for those who cannot tolerate or use TNF- $\alpha$ blockers, there is still an unmet need. ${ }^{14,15}$ Therefore, new medications that target different mechanisms of pathogenesis have been developed. In this paper, we review the rationale and current data for the use of abatacept, a selective $T$ cell costimulation inhibitor, in JIA with a polyarticular course.

\section{Role of T cells in pathogenesis of JIA}

Data on the pathogenesis of JIA are continuously accumulating, with research focusing on genetic factors and various pathways of the immune system. T cells have a crucial role in initiating the cascade of the immune response in JIA. Increased numbers of activated $\mathrm{CD}^{+}$and autoreactive $\mathrm{CD}^{+} \mathrm{T}$ cells are found in the circulation and the synovium of patients with JIA of polyarticular course. ${ }^{16}$ No specific antigens that trigger $\mathrm{T}$ cell activation have been recognized, but there are two major hypotheses on potential autoantigen groups. These include heat shock proteins and epitopes from the components of joint tissue found in the inflamed synovium. The synovial fluid from patients with JIA of polyarticular course was found to contain higher levels of cytokines (including interleukin [IL]-12) and chemokines that upregulate the immune response. ${ }^{16}$ Activated oligoclonal $\mathrm{T}$ cells that originate in the blood are concentrated in the synovial fluid in larger numbers in JIA. ${ }^{17}$ IL-17, produced by subsets of $\mathrm{CD}^{+}$cells in the synovium, was recognized to induce further local production of cytokines by synoviocytes, especially IL-6, IL-8, and matrix metalloproteinases that enhance joint destruction. IL-17 also suppresses Tregs $\left(\mathrm{CD} 4{ }^{+} \mathrm{CD} 25^{+}\right)$activity. Tregs have an important role in the process of autoimmune disease prevention, and have been found in decreased numbers in patients with JIA of polyarticular course compared with those having persistent oligoarthritis. ${ }^{18}$

\section{Abatacept}

The activation of $T$ cells involves two major steps. The first consists of the presentation of a peptide by an antigen-presenting cell to the $\mathrm{T}$ cell receptor (Figure 1). ${ }^{19}$ The second step can be one of several costimulation associations between ligands on the antigen-presenting cell and $\mathrm{T}$ cell receptors. One of the most important is the link between the CD80/CD86 ligand on antigen-presenting cells and CD28 on T cells. CTLA-4 (CD152) is a member of the CD28 immunoglobulin superfamily expressed on the $\mathrm{T}$ cell membrane. It has a structural resemblance to $\mathrm{CD} 28$, but its affinity to $\mathrm{CD} 80 / \mathrm{CD} 86$ is much higher. CD28 transmits a stimulatory effect, enhancing activation and upregulation of downstream pathways. CTLA-4 transmits an inhibitory signal to $\mathrm{T}$ cells and thus decreases activation of B cells, macrophages, and production of proinflammatory cytokines, and induces anergy. ${ }^{20} \mathrm{Abatacept}$ (CTLA-4 immunoglobulin) is a recombinant fully humanized fusion protein, composed of the extracellular domain of human CTLA-4 and a portion of the Fc-domain of human IgG-1 that was engineered to prevent complement fixation. ${ }^{21}$

Trials in adults with rheumatoid arthritis demonstrated improvement in disease control, health-related quality of life, and reduction in joint damage in patients who failed to 


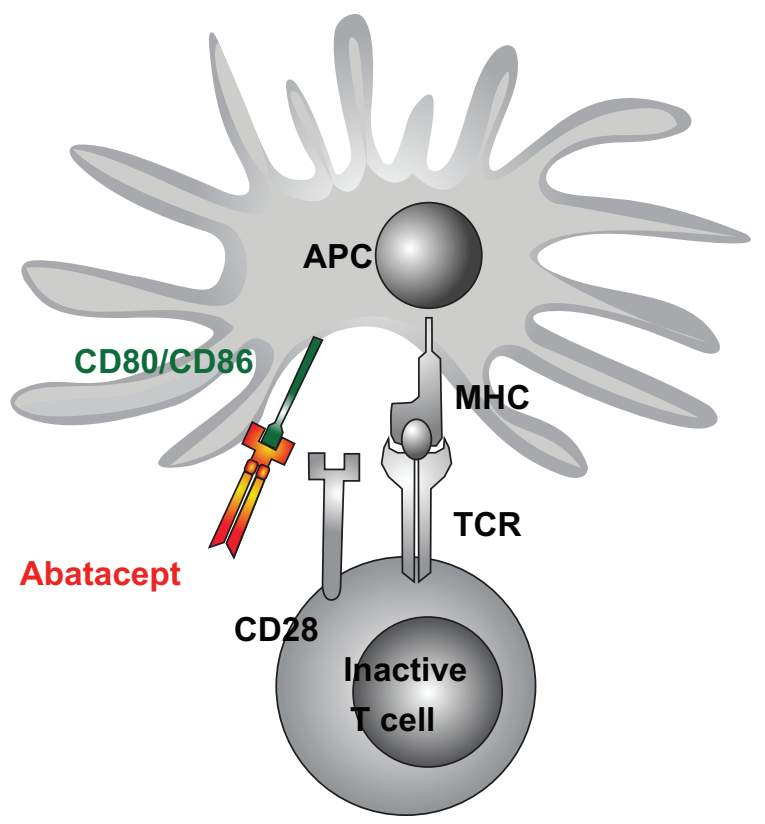

Figure I Schema of $\mathrm{T}$ cell activation and the inhibitory action of abatacept on costimulation. Copyright (C) 2008. Dove Medical Press. Reprinted with permission. Kuemmerle-Deschner JB, Benseler S. Abatacept in difficult-to-treat JIA. Biologics. 2008;2(4):865-874. .1 $^{1}$

Abbreviations: APC, antigen presenting cell; $\mathrm{MHC}$, major histocompatibility complex; TCR, T cell receptor.

respond to other disease-modifying antirheumatic drugs. ${ }^{22}$ Abatacept was approved for rheumatoid arthritis by the US Food and Drug Administration (FDA) in 2005.

\section{Pharmacokinetics and pharmacodynamics}

The pharmacokinetics of abatacept have not been specifically examined in children or adolescents, and are based on studies in healthy adults and patients with rheumatoid arthritis. ${ }^{23}$ Pharmacokinetics in healthy adults were examined after a single dose of abatacept and in rheumatoid arthritis patients after multiple doses of $10 \mathrm{mg} / \mathrm{kg}$ (both groups were comparable). ${ }^{24} \mathrm{The}$ mean volume of distribution was 0.07 (range $0.02-013$ ) L/kg. At steady state, the plasma concentration level achieved at day 60 was $24-295 \mu \mathrm{g} / \mathrm{mL}$. The half-life was 13.1 (range 8-25) days. The systemic clearance was $0.22 \mathrm{~mL} / \mathrm{kg} /$ hour, with a trend of increased clearance with increased body weight. Systemic accumulation was not demonstrated after prolonged therapy. Concomitant treatment with methotrexate, nonsteroidal antiinflammatory drugs, corticosteroids, or TNF- $\alpha$ blockers did not change the clearance. Pharmacokinetics were not affected by age and gender. The influence of renal or hepatic dysfunction on pharmacokinetics was not studied.

Abatacept pharmacodynamics at a dose of $10 \mathrm{mg} / \mathrm{kg}$ showed a decrease in serum levels of several cytokines and acute-phase reactants, particularly C-reactive protein, TNF- $\alpha$, IL-6, and metalloproteinase-3.

\section{Efficacy of abatacept in JIA of polyarticular course}

Abatacept was studied in a randomized, double-blind, placebo-controlled withdrawal trial performed in 45 centers in Europe and the US between 2004 and 2006. ${ }^{25}$ The study was conducted in European and South American centers of the Pediatric Rheumatology International Trials Organization and in the US by the Pediatric Rheumatology Collaborative Study Group. Children aged 6-17 years with a polyarticular course of JIA were enrolled, including patients with polyarthritis with and without rheumatoid factor, extended oligoarthritis, and systemic JIA without systemic manifestations for at least six months. At the time of enrollment, patients had to have at least two active joints and two joints with limited range of motion. Patients had to have failed or not tolerated at least one disease-modifying antirheumatic drug. Patients failing TNF- $\alpha$ blocking agents were allowed to enroll after an adequate washout period (four weeks for etanercept and eight weeks for infliximab and adalimumab). Exclusion criteria included active uveitis, pregnancy, lactation, or a major concurrent medical condition. Methotrexate was the only disease-modifying antirheumatic drug allowed during the controlled phase of the trial (hydroxychloroquine, sulfasalazine, and azathioprine were allowed during the open-label, long-term extension). Patients were primarily assessed using the American College of Rheumatology (ACR) Pediatric 30, an outcome tool developed in the 1990s that has been validated as an outcome measure in JIA trials (Table 2).$^{26}$ The proportions of patients with an ACR Pediatric 50, 70, 90, and 100 response were also assessed.

One hundred and ninety patients entered the open-label, lead-in phase of the study; 147 (77\%) were Caucasian, and 137 $(72 \%)$ were females (Figure 2). Rheumatoid factor-negative polyarthritis was the most common diagnosis (44\%). The mean disease duration was 4.2 years. Patients had a mean of 16 active joints. More than $70 \%$ were treated with concurrent methotrexate, and more than $30 \%$ had been treated unsuccessfully with at least one TNF- $\alpha$ blocking agent. In the first phase, all patients received abatacept $10 \mathrm{mg} / \mathrm{kg}$ (maximum $1000 \mathrm{mg}$ per dose) on days 1, 15, 29, 57, and 85. Seventeen patients discontinued because the treatment was ineffective, one withdrew because of an adverse effect, one was lost to follow-up, and no reason was stated for one patient. By the end of the lead-in phase, 123 subjects $(65 \%)$ were considered 
Table 2 Outcome measures for clinical trials in juvenile idiopathic arthritis validated by the American College of Rheumatology ${ }^{26}$

- Active joint count (joints with swelling or tender/pain on motion and limitation of motion)

- Joints with limited range of motion

- Parent/patient global assessment (measured on a 0-10 VAS)

- Physician global assessment (measured on a 0-10 VAS)

- Laboratory measure of inflammation (erythrocyte sedimentation rate, C-reactive protein)

- Functional assessment (Childhood Health Assessment Questionnaire) Notes: ACR Pediatric 30 response: A patient is considered to have responded if there has been an improvement in at least three variables by at least $30 \%$ and worsening in not more than one variable by more than $30 \%$. Flare: A patient is considered to flare if there has been worsening of $30 \%$ or more in at least three of the six variables and at least $30 \%$ improvement in no more than one variable. A minimum change of $20 \mathrm{~mm}$ in global assessment and at least two additional active joints is necessary.

Abbreviation: VAS, visual analog scale.

responders at least at an ACR Pediatric 30 response level. Twenty-four (13\%) patients attained a status of inactive disease (definition in Table 3). There were no significant differences in response rates between the various categories of JIA with a polyarticular course.

The pivotal phase was double-blind withdrawal randomization to abatacept versus placebo. One hundred and twenty-two subjects (one eligible subject left the study before randomization) entered this phase on day 113, with 60 randomized to abatacept and 62 to placebo infusion (Figure 2). Treatment was administered every 28 days until the development of an arthritis flare (definition in Table 2A) for up to six months. The primary outcome was the number of patients in each arm of the study who flared within these six months. Secondary outcomes included safety and tolerability of the drug, median time to disease flare, and other ACR Pediatric response rates at the end of six months. The number of patients who developed a flare was significantly lower in the abatacept group compared with the placebo group (12 [20\%] versus 33 [53\%], respectively, $P=0.0003$ ). The median time to flare in the placebo group was six months, but no calculation was possible in the abatacept groups due to insufficient events. Significantly more patients in the abatacept group achieved an ACR Pediatric 50, 70, and 90 response rate, as well as inactive disease status, than in the placebo group (Table 4). A full six months was completed

Table 3 Definition of inactive disease. ${ }^{6}$

- No joints with active disease

- Normal erythrocyte sedimentation rate $(<20 \mathrm{~mm} / \mathrm{hour})$

- Physician global assessment of $10 \mathrm{~mm}$ or less

- No uveitis by $49(82 \%)$ patients in the abatacept group and $31(50 \%)$ in the placebo group.

Following this phase was an open-label, long-term, extension period in which patients were given the option to continue treatment with abatacept for up to five years. ${ }^{27}$ Subjects included in this phase belonged to several groups, ie, patients treated continuously with abatacept, those with a flare during the double-blind phase, and six-month completers regardless of the treatment arm. Patients who did not achieve an ACR Pediatric 30 after the open-label phase were also allowed to enter the long-term extension. Patients were assessed by joint examination and physician's global assessment of disease severity.

Forty-two of 153 subjects who started this phase discontinued treatment early; 20 due to lack of effect (more than half were from the group of the initial nonresponders) and three because of adverse effects. Patients were treated for a median of 35 (range 5.5-47.8) months. More than 50\% were treated for at least three years. Fifty-one patients were treated continuously with abatacept, and treatment was interrupted in 47 patients due to having received placebo during the doubleblind phase. ACR Pediatric response rates at day 589 did not significantly differ between these two groups (Table 3 ). However, significantly more patients in the continuous group (22 patients, 43\%) attained the status of inactive disease than in the interrupted group (11 patients, 22\%).

Sixteen of the 36 patients who did not achieve an ACR Pediatric 30 by the end of the open-label lead-in phase who entered the long-term extension phase stopped treatment early; 11 because of loss of efficacy, one because of loss to follow-up, and four without a documented reason. The response rate of this group was lower than those who responded in the open-label, lead-in phase, with only one subject attaining the status of inactive disease (Table 4). However, it is important to note that there was still a large number of responders (including at high levels of an ACR Pediatric 50 and 70 response) indicating that a long trial of abatacept (even six months) may be necessary before a patient is considered to have failed treatment.

\section{Patients naïve to TNF- $\alpha$ blockade versus TNF- $\alpha$ blockade failures}

AWAKEN (Abatacept Withdrawal study to Assess efficacy and safety in Key ENdpoints) was the first trial to include JIA patients who had failed TNF- $\alpha$ blockade. One hundred and thirty $(70 \%)$ of the subjects in the AWAKEN trial were naïve to TNF- $\alpha$ blockade. By the end of the open-label, lead-in phase, 101 (76\%) achieved an ACR Pediatric 30 response, compared with 57 (39\%) patients who failed 


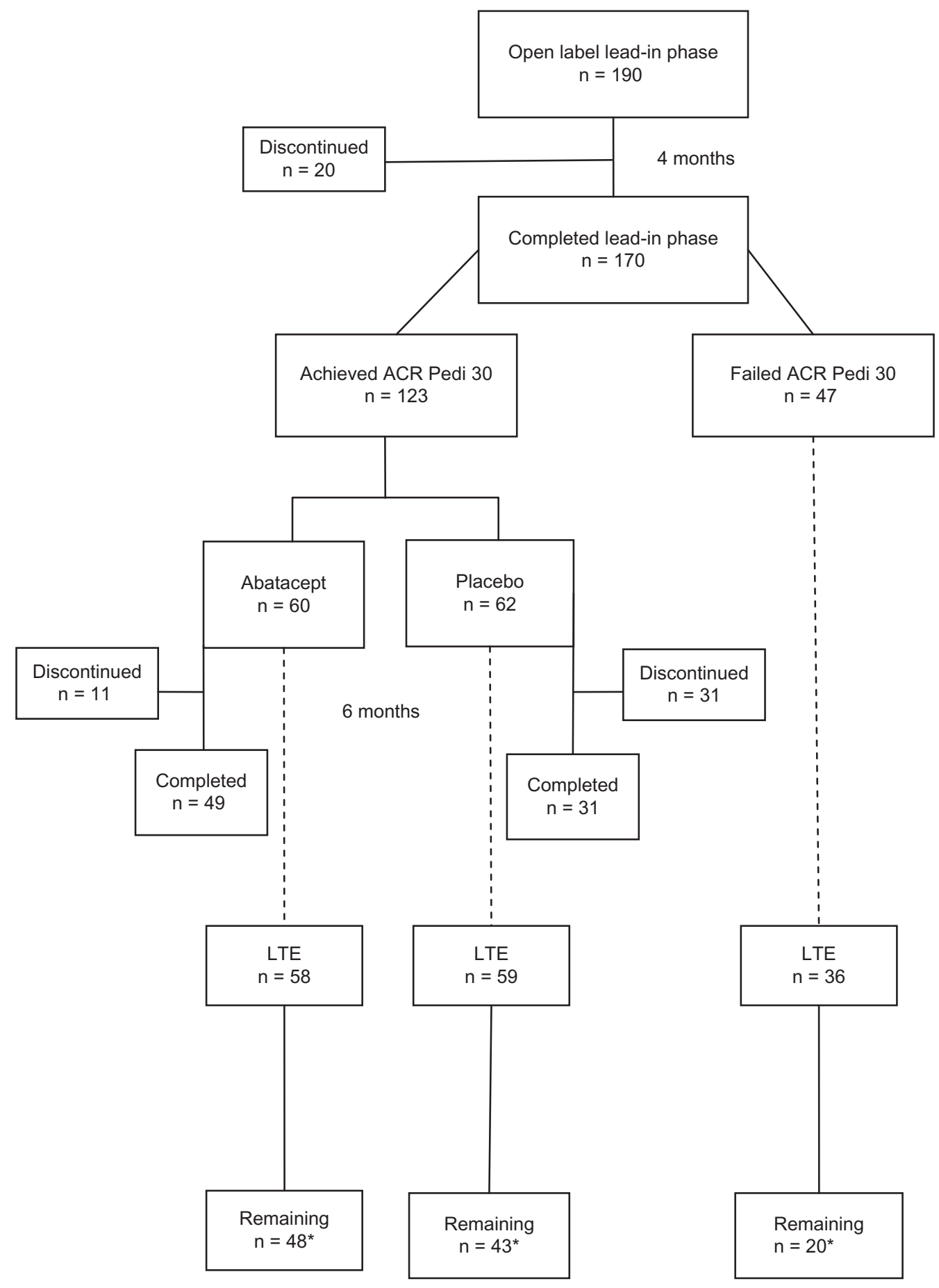

Figure 2 A flow chart of patient disposition in various phases of the abatacept trial. ${ }^{27}$ Note: One responder was not randomized.

Abbreviations: ACR, American College of Rheumatology; Pedi, pediatric; LTE, long-term extension.

TNF- $\alpha$ blocking agents in the past. The response rate of continuous abatacept treatment on day 589 was similar among the TNF- $\alpha$ blockade-naïve subjects $(\mathrm{n}=46)$ and TNF- $\alpha$ blocking agent failures $(n=5)$. However, inactive disease status was attained in $46 \%$ of the TNF- $\alpha$ blockadenaïve group, versus $20 \%$ in the latter group (Table 5). The response rate for interrupted abatacept (placebo during the double-blind phase and reintroduction of abatacept during the long-term extension) treatment was greater among the TNF- $\alpha$ blockade-naïve group than the TNF- $\alpha$ blocking agent failures, especially among those who attained a high response rate and/or inactive disease status (Table 5). No 
Table 4 Response (percent) to therapy during various phases of the trial

\begin{tabular}{|c|c|c|c|c|c|c|}
\hline Percent of patients achieving Level & Pedi 30 & Pedi 50 & Pedi 70 & Pedi 90 & Pedi 100 & Inactive disease \\
\hline Lead-in open-label $(n=190)$ & 65 & 50 & 28 & 13 & NA & 13 \\
\hline DB abatacept $(n=60)$ & 82 & $77^{*}$ & $53^{*}$ & $40 *$ & NA & $30 *$ \\
\hline DB placebo $(n=62)$ & 69 & $52 *$ & $3 I^{*}$ & $16 *$ & NA & $11 *$ \\
\hline LTE continuous abatacept $(n=51)$, day 589 & 90 & 88 & 75 & 57 & 20 & $43^{*}$ \\
\hline LTE interrupted treatment ${ }^{\mathrm{a}}(n=47)$, day 589 & 87 & 83 & 75 & 40 & 19 & $22 *$ \\
\hline LTE lead-in phase nonresponders $(n=22)$, day 589 & 73 & 64 & $46 *$ & $18 *$ & 0* & $3^{*}$ \\
\hline
\end{tabular}

Notes: aPatients who received placebo during the double-blind withdrawal phase; *Statistically significant differences.

Abbreviations: Pedi, American College of Rheumatology pediatric response rate; DB, double blind; LTE, Open-label long-term extension; NA, not available.

significant differences in response rates between TNF- $\alpha$ blockade-naïve and failures were found in nonresponders in the open-label, lead-in phase who continued to the long-term extension. Among the five TNF- $\alpha$ blocking agent failures, $80 \%, 60 \%$, and $20 \%$ achieved an ACR Pediatric 30, 50, and 70 response rate, respectively.

\section{Health-related quality of life, pain, sleep, and daily activities}

Abatacept improves many aspects of the children's healthrelated quality of life. ${ }^{28}$ Health-related quality of life were assessed using the Child Health Questionnaire (CHQ), a validated tool translated into 32 languages. Two summary scores, ie, the physical summary score and the psychosocial summary score, were calculated from analysis of 10 of $15 \mathrm{CHQ}$ domains. Results were compared with healthy individuals. ${ }^{29}$ Pain was assessed by parents or caregivers using a $100 \mathrm{~mm}$ visual analog scale in which a higher score is worse. Sleep was assessed using the Children's Sleep Habits Questionnaire which includes the following subcategories: bedtime resistance, sleep onset delay, sleep duration, sleep anxiety, night waking, parasomnias, sleep-disordered breathing, and daytime sleepiness. Total scores of 1-100 correlate directly with the magnitude of sleep disturbances. Participation in daily activities was assessed with a questionnaire that addressed school attendance and the effect of JIA on the child and caregivers' daily activities over the 30 days prior to answering.
All assessments were performed three times in the open-label lead-in and the controlled withdrawal phases of the trial.

Health-related quality of life parameters were significantly decreased in the study subjects when compared with healthy children at baseline, such as global health, physical function, role/social limitations (emotional, role/social limitation), physical and pain/discomfort. These improved significantly by the end of the open label, lead-in phase, with the physical summary score increasing in ACR Pediatric 30 responders to 42.5 (maximum $=55)$ at day 113 . During the controlled withdrawal phase, health-related quality of life continued to improve in subjects who were randomized to continue abatacept, but stabilized or worsened in the placebo group. Pain was reduced in all subjects during the open-label, lead-in phase and in abatacept-treated patients during the controlled withdrawal phase. However, pain increased in the placebo-treated group. Reduction of pain was observed also in patients who did not achieve an ACR Pediatric 30 response after the lead-in phase.

Following the open-label, lead-in phase, sleep index scores improved among ACR Pediatric 30 responders, mainly in the domains of bedtime resistance, parasomnias, and daytime sleepiness. Sleep continued to improve in the abatacept-treated subjects during the controlled withdrawal phase, but deteriorated in the placebo-treated subjects.

Following the open-label, lead-in phase, the ACR Pediatric 30 responders missed fewer school days (2.6) per month and

Table 5 Comparison of the response rate (percent) of patients who were TNF- $\alpha$ blockade-naïve versus TNF- $\alpha$ blockade failures at day 589 of the open-label long-term extension period

\begin{tabular}{|c|c|c|c|c|c|c|}
\hline Patients achieving level (\%) & Pedi 30 & Pedi 50 & Pedi 70 & Pedi 90 & Pedi 100 & Inactive disease \\
\hline Continuous abatacept, TNF- $\alpha$ blockade-naïve $(n=46)$ & 89 & 87 & 76 & 57 & 39 & 46 \\
\hline Continuous abatacept, TNF- $\alpha$ blockade failure $(n=5)$ & 100 & 100 & 60 & 60 & 40 & 20 \\
\hline Interrupted abatacept, TNF- $\alpha$ blockade-naïve $(n=4$ I) & 90 & 88 & $81 *$ & $46^{*}$ & $22 *$ & $24 *$ \\
\hline Interrupted abatacept, TNF- $\alpha$ blockade failure $(n=6)$ & 67 & 50 & $33 *$ & $0 *$ & $0 *$ & $I^{*}$ \\
\hline Nonresponders in lead-in phase, TNF- $\alpha$ blockade-naïve $(n=17)$ & 71 & 65 & $53 *$ & $24 *$ & 6 & 6 \\
\hline Nonresponders in lead-in phase, TNF- $\alpha$ blockade failure $(n=5)$ & 80 & 60 & $20 *$ & $0 *$ & 0 & 0 \\
\hline
\end{tabular}

Note: *Statistically significant difference.

Abbreviations: Pedi, American College of Rheumatology pediatric response rate; TNF- $\alpha$, tumor necrosis factor alpha. 
their parents missed fewer days (2.3) of their normal activities. These effects continued only among abatacept-treated subjects during the controlled withdrawal phase.

\section{Safety}

The safety profile of abatacept was generally good and essentially remained unchanged during all phases of the study (Table 6). In the open-label, lead-in phase, six subjects had serious adverse events that included arthritis flare in two patients and arthropathy in another. There was one case each of varicella infection, ovarian cyst, and acute lymphoblastic leukemia diagnosed at day 89. The latter patient may have been misdiagnosed with JIA. Adverse events were documented in $133(70 \%)$ subjects. The most common adverse events were headache (13\%), nausea (10\%), cough, diarrhea ( $9 \%$ each), upper respiratory tract infection (7\%), and pyrexia (6\%). Mild infusion reactions were documented in eight patients $(4 \%)$. These included headache and dizziness and did not recur.

In the controlled withdrawal phase, no serious adverse events were documented in the abatacept group. There were two serious adverse events in the placebo group that included

Table 6 Summary of safety data from abatacept studies

\begin{tabular}{|c|c|c|}
\hline & $\begin{array}{l}\text { Open-label, lead-in } \\
\text { and controlled } \\
\text { withdrawal phases }\end{array}$ & $\begin{array}{l}\text { Open-label, } \\
\text { long-term } \\
\text { extension }\end{array}$ \\
\hline Number of patients & 190 & 153 \\
\hline Study length (months) & 10 & 35 (47.8 maximum) \\
\hline Patient-year exposure & NA & NA \\
\hline Adverse events (total) & 170 & NA \\
\hline $\begin{array}{l}\text { Serious adverse events } \\
\text { (total) }\end{array}$ & 6 & 23 \\
\hline $\begin{array}{l}\text { Adverse events leading } \\
\text { to drug discontinuation }\end{array}$ & I & 3 \\
\hline Infusion reactions & 9 & I5 (5 patients) \\
\hline Anaphylaxis-like reactions & 0 & 2 \\
\hline Infections (total) & 95 & NA \\
\hline Serious infections & I & 6 \\
\hline Mycobacterium infections & 0 & 0 \\
\hline $\begin{array}{l}\text { Other opportunistic } \\
\text { infections }\end{array}$ & 0 & I \\
\hline $\begin{array}{l}\text { Autoimmune phenomena } \\
\text { (total) }\end{array}$ & 0 & 0 \\
\hline Uveitis & 0 & I \\
\hline Demyelinating events & 0 & I \\
\hline “Lupus-like” syndrome & 0 & 0 \\
\hline Autoantibodies & 14 & 4 \\
\hline Antibodies to medication & NA & 17 \\
\hline Malignancies (total) & $\mathrm{I}^{*}$ & 0 \\
\hline Deaths & 0 & 0 \\
\hline
\end{tabular}

Note: *Malignancy may have been prior to treatment and patient was misdiagnosed with juvenile idiopathic arthritis.

Adapted from Hashkes et al. ${ }^{15}$

Abbreviation: NA, not available. hematoma and varicella with encephalitis. Both resolved without sequelae. In regards to serious adverse events in the placebo group, it is important to note that these patients received four months of abatacept, and a long-term effect of abatacept on the immune system cannot be ruled out. Adverse events were reported in $37(62 \%)$ from the abatacept group and $34(55 \%)$ among placebo recipients $(P=0.47)$, with mild infections being the most frequent. Mild infusion reactions occurred in $2 \%-3 \%$ of patients in both study arms. No other serious infections, autoimmune disorders, or anaphylaxis developed.

In the long-term extension, 23 subjects developed serious adverse events (Table 6). These included arthritis flare $(n=6)$, arthralgia, foot deformity, pyrexia, and vomiting $(n=2$ each). The most common adverse events were infections, with nasopharyngitis developing in $17.6 \%$, upper respiratory tract infections in $16.3 \%$, vomiting in $15 \%$, and pyrexia in $14 \%$. Serious infections developed in six subjects, including dengue fever, erysipelas, gastroenteritis, herpes zoster, bacterial meningitis, and pyelonephritis. One case of uveitis and four cases of benign neoplasm developed. One patient developed multiple sclerosis. No cases of mycobacterium, opportunistic infections, or malignancies were observed. Mild infusion reactions were uncommon. There were no significant laboratory abnormalities. Following the openlabel, lead-in phase, antinuclear antibodies developed in 12 of $113(10.6 \%)$ subjects who were initially antinuclear antibody-negative. In the double-blind phase, new antinuclear antibodies developed in two $(6 \%)$ of the abatacept group and one $(2 \%)$ in the placebo group. The development of double-stranded DNA antibodies was rare. None of those who developed autoantibodies developed autoimmune disease. Antibodies to abatacept or to CTLA-4 developed in 23\% of the patients. Their presence did not influence the efficacy or safety of abatacept.

A 2009 FDA pediatric advisory committee meeting looked at five-year postmarketing data of 90 patients treated with abatacept for up to 10 years until the age of 17 years. ${ }^{30}$ Six serious adverse events (four in the US) were reported. Four patients were treated for JIA and three for other indications. Serious adverse events included the aforementioned case of multiple sclerosis and lymphoma that occurred one month after starting abatacept. This patient had vasculitis and was treated with many prior immunosuppressive medications. The FDA has requested postmarketing follow-up of 500 abatacept-treated patients.

In a small series, neutralizing antibodies to abatacept were found in six of nine $(67 \%)$ of rheumatoid 
factor-positive patients. ${ }^{31}$ However, these antibodies were not associated with disease flare or adverse events. Antibodies were found more often when abatacept concentrations were below therapeutic levels.

\section{Indications and practical issues}

In 2008, the FDA approved abatacept for use in children older than six years with moderate to severe JIA of polyarticular course. The drug can be used as monotherapy or in conjunction with other nonbiologic disease-modifying antirheumatic drugs. In 2010, the European Medicines Agency approved abatacept in combination with methotrexate only in children who have failed disease-modifying antirheumatic drugs and at least one TNF- $\alpha$ blockade agent.

Abatacept is administered as an intravenous infusion over a period of 30 minutes. It is given every two weeks during the first month and then every four weeks at a dose of $10 \mathrm{mg} / \mathrm{kg}$ (maximum $1000 \mathrm{mg}$ ). Premedication for infusion reactions is not necessary. Tuberculosis and viral hepatitis status should be checked before treatment. Live vaccines should be avoided while taking the medication and until three months after discontinuation of the drug. Abatacept contains maltose that can cause a false elevation of blood glucose for up to one day after the infusion.

In a recent study from Canada, the costs of biologics versus conventional therapy in patients having JIA with a polyarticular course who failed or were intolerant to disease-modifying antirheumatic drugs, were calculated. ${ }^{32}$ The study compared the costs (direct and indirect, eg, cost of adverse events) involved in giving etanercept, infliximab, adalimumab, and abatacept for one year in order to attain an additional patient who achieved an ACR Pediatric 30 response status. Of the four drugs, abatacept was the least expensive, with a cost of US $\$ 16,205$ per year to achieve one patient with an ACR Pediatric 30 response.

\section{Abatacept versus TNF- $\alpha$ blockers}

The lack of head-to-head studies makes it difficult to compare these medications accurately. It appears that the efficacy is comparable, with a similar proportion of patients experiencing an ACR Pediatric 30 and higher levels of response. ${ }^{10-12,25}$ However, abatacept may take somewhat longer to achieve a response than TNF- $\alpha$ blockers. The time to flare appears to be longer, and the proportions of patients who flare appears to be smaller when abatacept is withdrawn compared with TNF- $\alpha$ blockers. In regards to safety issues, the number of patient-years of use for abatacept is still insufficient to compare it with TNF- $\alpha$ blockers, particularly for malignancies.
However, there do not appear to be significant differences regarding serious infectious adverse events, with the exception of mycobacterium infections, which are probably less common in abatacept-treated patients. ${ }^{15}$ Infusion reactions occur less frequently with abatacept than with infliximab.

\section{Future indications and directions in JIA}

Several case series have reported on the successful use of abatacept for JIA-related uveitis among TNF- $\alpha$ blockade failures. ${ }^{33,34}$ No studies have been published on the use of abatacept for systemic (with active systemic features), juvenile psoriatic, and enthesitis-related arthritis. Studies directly comparing abatacept with TNF- $\alpha$ blocking agents, abatacept with or without methotrexate, and abatacept use in early polyarthritis have not been performed. The effect of abatacept on the progression of radiologic damage as seen in adults should be investigated in the pediatric setting using newly validated pediatric measures. ${ }^{35,36}$ Recent reports in adults showing that subcutaneous abatacept may be as effective as the intravenous route, and may offer a new, easier method of administration in children. ${ }^{37}$

\section{Potential of genomic medicine}

In the future, it will be possible to personalize and adjust correct treatment for the individual patient. The protein tyrosine phosphatase nonreceptor type (PTPN) 22 gene, located on chromosome $1 \mathrm{p} 13.3-13.1$, encodes for a tyrosine phosphatase that downregulates the activation of T lymphocytes mediated by CD28 costimulation. ${ }^{38} \mathrm{~A}$ single nucleotide polymorphism in the PTPN22 gene (C1858T) causes a decrease in its activity. This polymorphism is more commonly found in patients with rheumatoid arthritis, rheumatoid factor-negative polyarthritis JIA, oligoarthritis, systemic lupus erythematosus, and diabetes mellitus. ${ }^{39,40}$ Due to the effect of this polymorphism in enhancing $\mathrm{T}$ cell costimulation, there is an as yet untested hypothesis that abatacept will be more effective in patients with this polymorphism. ${ }^{41}$ Genomic medicine may also enable us to predict which patients are more likely to fail TNF- $\alpha$ blockade therapy and benefit from earlier use of abatacept.

\section{Conclusion}

Abatacept is an immune-modulating drug, targeting $\mathrm{T}$ cell activation by interfering with one of the costimulatory mechanisms that are essential for cell activation. The drug is effective in patients with moderate to severe JIA of polyarticular course, either as monotherapy or in combination with other 
nonbiologic disease-modifying antirheumatic drugs. Even after more than three years of use, the drug remains safe, with rare serious adverse events. However, long-term postmarketing surveillance is necessary. For some patients, the time to response from the start of treatment may take as long as six months. In most patients, abatacept continues to be effective for at least three years. There is also a significant positive effect of abatacept on various aspects of health-related quality of life. Furthermore, abatacept may be more cost-effective than TNF- $\alpha$ blocking agents in treating patients with JIA of polyarticular course. Therefore, it is possible that the European Medicines Agency indication may be modified to allow for earlier use of abatacept, even prior to TNF- $\alpha$ blockade failure. Future studies may include new indications for abatacept in other categories of JIA and JIA-related uveitis, as well as the optimal timing of abatacept use in relation to disease onset. In the future, we might be able to tailor the use of abatacept for patients whose genetics will predict a better response.

\section{Disclosure}

The authors report no conflicts of interests in this work.

\section{References}

1. Ravelli A, Martini A. Juvenile idiopathic arthritis. Lancet. 2007; 369(9563):767-778.

2. Wallace CA, Levinson JE. Juvenile rheumatoid arthritis: Outcome and treatment for the 1990s. Rheum Dis Clin North Am. 1991;17(4): 891-905.

3. Packham JC, Hall MA, Pimm TJ. Long-term follow-up of 246 adults with JIA: Predictive factors for mood and pain. Rheumatology (Oxford). 2002;41(12):1444-1449.

4. Minden K. Adult outcomes of patients with JIA. Horm Res. 2009; 72 Suppl 1:20-25.

5. Ruperto N, Levinson JE, Ravelli A, et al. Long-term health outcomes and quality of life in American and Italian inception cohorts of patients with juvenile rheumatoid arthritis. I. Outcome status. J Rheumatol. 1997;24(5):945-951.

6. Wallace CA, Huang B, Bandeira M, Ravelli A, Giannini EH. Patterns of clinical remission in select categories of JIA. Arthritis Rheum. 2005; 52(11):3554-3562.

7. Hashkes PJ, Laxer RM. Medical treatment of JIA. JAMA. 2005; 294(13):1671-1684.

8. Giannini EH, Brewer EJ, Kuzmina N, et al. Methotrexate in resistant juvenile rheumatoid arthritis. Results of the USA-USSR. double-blind, placebo-controlled trial. The Pediatric Rheumatology Collaborative Study Group and The Cooperative Children's Study Group. N Engl J Med. 1992;326(16):1043-1049.

9. Ruperto N, Murray KJ, Gerloni V, et al. A randomized trial of parenteral methotrexate comparing an intermediate dose with a higher dose in children with JIA who failed to respond to standard doses of methotrexate. Arthritis Rheum. 2004;50(7):2191-2201.

10. Lovell DJ, Giannini EH, Reiff A, et al. Etanercept in children with polyarticular juvenile rheumatoid arthritis. Pediatric Rheumatology Collaborative Study Group. N Engl J Med. 2000;342(11):763-769.

11. Ruperto N, Lovell DJ, Cuttica R, et al. A randomized, placebo-controlled trial of infliximab plus methotrexate for the treatment of polyarticularcourse juvenile rheumatoid arthritis. Arthritis Rheum. 2007;56(9): 3096-3106.
12. Lovell DJ, Ruperto N, Goodman S, et al. Adalimumab with or without methotrexate in juvenile rheumatoid arthritis. $N$ Engl J Med. 2008; 359(8):810-820.

13. Ringold S, Seidel KD, Koepsell TD, Wallace CA. Inactive disease in polyarticular JIA: Current patterns and associations. Rheumatology (Oxford). 2009;48(8):972-977.

14. Lovell DJ, Reiff A, Ilowite NT, et al. Safety and efficacy of up to eight years of continuous etanercept therapy in patients with juvenile rheumatoid arthritis. Arthritis Rheum. 2008;58(5):1496-1504.

15. Hashkes PJ, Uziel Y, Laxer RM. The safety profile of biologic therapies for JIA. Nat Rev Rheumatol. 2010;6(10):561-571.

16. Macaubas C, Nguyen K, Milojevic D, Park JL, Mellins ED. Oligoarticular and polyarticular JIA: Epidemiology and pathogenesis. Nat Rev Rheumatol. 2009;5(11):616-626.

17. Nistala K, Wedderburn LR. Th17 and regulatory T cells: Rebalancing pro- and anti-inflammatory forces in autoimmune arthritis. Rheumatology (Oxford). 2009;48(6):602-606.

18. Prakken BJ, Albani S. Using biology of disease to understand and guide therapy of JIA. Best Pract Res Clin Rheumatol. 2009;23(5): 599-608.

19. Hervey PS, Keam SJ. Abatacept. BioDrugs. 2006;20(1):53-61.

20. Goeb V, Buch MH, Vital EM, Emery P. Costimulation blockade in rheumatic diseases: Where we are? Curr Opin Rheumatol. 2009; 21(3):244-250.

21. Graca L. CTLA4Ig and the therapeutic potential of T cell co-stimulation blockade. Acta Reumatol Port. 2008;33(3):267-276. [Portuguese].

22. Genovese MC, Schiff M, Luggen M, et al. Efficacy and safety of the selective co-stimulation modulator abatacept following 2 years of treatment in patients with rheumatoid arthritis and an inadequate response to anti-tumour necrosis factor therapy. Ann Rheum Dis. 2008; 67(4):547-554.

23. Orencia ${ }^{\circledR}$ [Package insert]. Princeton, NJ: Bristol-Myers Squibb Company; Aug 2009.

24. Bruce SP, Boyce EG. Update on abatacept: A selective costimulation modulator for rheumatoid arthritis. Ann Pharmacother. 2007; 41(7):1153-1162.

25. Ruperto N, Lovell DJ, Quartier P, et al. Abatacept in children with JIA: A randomised, double-blind, placebo-controlled withdrawal trial. Lancet. 2008:372(9636):383-391.

26. Giannini EH, Ruperto N, Ravelli A, Lovell DJ, Felson DT, Martini A. Preliminary definition of improvement in juvenile arthritis. Arthritis Rheum. 1997;40(7):1202-1209.

27. Ruperto N, Lovell DJ, Quartier P, et al; Paediatric Rheumatology International Trials Organization and the Pediatric Rheumatology Collaborative Study Group. Long-term safety and efficacy of abatacept in children with juvenile idiopathic arthritis. Arthritis Rheum. 2010; 62(6):1792-1802.

28. Ruperto N, Lovell DJ, Li T, et al. Abatacept improves health-related quality of life, pain, sleep quality and daily participation in subjects with JIA. Arthritis Care Res (Hoboken). 2010;62(11):1542-1551.

29. Ruperto N, Ravelli A, Pistorio A, et al. Cross-cultural adaptation and psychometric evaluation of the Childhood Health Assessment Questionnaire (CHAQ) and the Child Health Questionnaire (CHQ) in 32 countries. Review of the general methodology. Clin Exp Rheumatol. 2001;19(4 Supp1 23):S1-S9.

30. Durmoqicz EL. Pediatric focused safety review. FDA [online]. Available from: http://www.fda.gov/downloads/AdvisoryCommittees/ CommitteesMeeting Materials/PediatricAdvisoryCommittee/ ucm193143.pdf. Accessed 2010 Dec 21.

31. Kuemmerle-Deschner JB, Benseler S. Abatacept in difficult-to-treat JIA. Biologics. 2008;2(4):865-874.

32. Ungar WJ, Costa V, Hancock-Howard R, Feldman BM, Laxer RM. Cost-effectiveness of biologics in polyarticular-course JIA patients unresponsive to disease modifying anti-rheumatic drugs. Arthritis Care Res (Hoboken).2011;63(1):111-119.

33. Zulian F, Balzarin M, Falcini F, et al. Abatacept for severe anti-tumor necrosis factor alpha refractory JIA-related uveitis. Arthritis Care Res (Hoboken). 2010;62(6):821-825. 
34. Kenawy N, Cleary G, Mewar D, Beare N, Chandna A, Pearce I. Abatacept: A potential therapy in refractory cases of JIA-associated uveitis. Graefes Arch Clin Exp Ophthalmol. Oct 5 2010. [Epub ahead of print].

35. Emery P, Durez P, Dougados M, et al. Impact of T-cell costimulation modulation in patients with undifferentiated inflammatory arthritis or very early rheumatoid arthritis: A clinical and imaging study of abatacept (the ADJUST trial). Ann Rheum Dis. 2010;69(3):510-516.

36. Ravelli A, Ioseliani M, Norambuena X, et al. Adapted versions of the Sharp/ van der Heijde score are reliable and valid for assessment of radiographic progression in JIA. Arthritis Rheum. 2007;56(9): 3087-3095.

37. Keystone EC, Kremer JM, Russell AS, et al. Switching patients with rheumatoid arthritis (RA) from intravenous (IV) to subcutaneous (SC) abatacept is well tolerated and sustains previously established efficacy [Abstract]. Arthritis Rheum. 2010;62(10 Suppl):S176.
38. Hinks A, Worthington J, Thomson W. The association of PTPN22 with rheumatoid arthritis and JIA. Rheumatology (Oxford). 2006; 45(4):365-368.

39. Lee YH, Rho YH, Choi SJ, et al. The PTPN22 C1858T functional polymorphism and autoimmune diseases - a meta-analysis. Rheumatology (Oxford). 2007;46(1):49-56.

40. Thompson SD, Sudman M, Ramos PS, et al. The susceptibility loci JIA shares with other autoimmune diseases extend to PTPN2, COG6, and ANGPT1. Arthritis Rheum. 2010;62(11):3265-3276.

41. Gregersen PK, Lee HS, Batliwalla F, Begovich AB. PTPN22: Setting thresholds for autoimmunity. Semin Immunol. 2006;18(4):214-223.

\section{Publish your work in this journal}

Drug Design, Development and Therapy is an international, peerreviewed open-access journal that spans the spectrum of drug design and development through to clinical applications. Clinical outcomes, patient safety, and programs for the development and effective, safe, and sustained use of medicines are a feature of the journal, which has also been accepted for indexing on PubMed Central. The manuscript management system is completely online and includes a very quick and fair peer-review system, which is all easy to use. Visit http://www.dovepress.com/testimonials.php to read real quotes from published authors.

Submit your manuscript here: http://www.dovepress.com/drug-design-development-and-therapy-journal 